\title{
FAKTOR RISIKO HIPERTENSI DI KELURAHAN SUNGAI ASAM WILAYAH KERJA PUSKESMAS KONI KOTA JAMBI
}

\author{
Risk Factors Of Hypertension in Sungai Asam Village At Working Area Of The Koni Public \\ Health Center, Jambi City
}

\author{
Dena Tri Solehaini ${ }^{1}$, Willia Novita Eka Rini ${ }^{2}$, dan Asparian ${ }^{2}$ \\ ${ }^{1}$ Mahasiswa Program Studi Ilmu Kesehatan Masyarakat FKM Universitas Jambi \\ ${ }^{2}$ Dosen Program Studi Ilmu Kesehatan Masyarakat FKM Universitas Jambi
}

\begin{abstract}
Abstrak
Hipertensi esensial lebih banyak dialami masyarakat Indonesia karena cenderung dipengaruhi faktor genetik dan didukung faktor risiko lainnya. Tujuan penelitian untuk mengetahui gambaran dan hubungan antara faktor risiko dengan hipertensi. Metode penelitian ini adalah Studi observasional dengan rancangan cross sectional. Sampel berjumlah 200 orang berumur $\geq 15$ tahun dipilih menggunakan multistage sampling atau two stage cluster sampling. Penelitian dilakukan di Kelurahan Sungai Asam Wilayah Kerja Puskesmas Koni Kota Jambi pada tahun 2018. Analisis data menggunakan uji Chi Square. Hasil: Proporsi hipertensi di Kelurahan Sungai Asam sebesar 53,5\%. Dari 200 orang responden ditemukan sebanyak 60\% memiliki riwayat keluarga dan paling besar berasal dari ibu kandung (59,4\%), 84\% mengalami stres, $80 \%$ mengonsumsi garam $>2000 \mathrm{mg}$ per hari, $69 \%$ mengonsumsi makanan berlemak $>67$ gram per hari, $94 \%$ mengonsumsi sayur dan buah <400 gram per hari (94\%), dan $88 \%$ menggunakan tembakau dan paling besar adalah perokok pasif $(64,4 \%)$. Tingginya proporsi hipertensi berhubungan beberapa faktor risiko yang diteliti diantaranya konsumsi makanan berlemak (nilai $\mathrm{P}=$ 0,000; POR $=32,300 ; 95 \% \mathrm{CI}=12,002-86,925)$, stres (nilai $\mathrm{P}=0,000 ; \mathrm{POR}=8,345 ; 95 \% \mathrm{CI}=3,060-22,758$ ), riwayat keluarga (nilai $\mathrm{P}=0,000$; $\mathrm{POR}=7,106$; dan 95\% $\mathrm{CI}=3,759-13,436$ ), konsumsi garam (nilai $\mathrm{P}=0,000$; $\mathrm{POR}=5,444 ; 95 \% \mathrm{CI}=2,428-12,207)$. Kesimpulan: Hipertensi terbukti berhubungan dengan riwayat keluarga dan faktor risiko lainnya. Oleh karena itu, masyarakat perlu memperbaiki gaya hidup yang berisiko menimbulkan hipertensi terutama yang memiliki riwayat hipertensi pada keluarga.
\end{abstract}

Kata Kunci: Faktor Risiko, Hipertensi, Kelurahan Sungai Asam

\begin{abstract}
Background: Essential hypertension was more common than other types of hypertension among Indonesian people. Essential hypertension tends to be influenced by family history and supported by other risk factors. The purpose of this study was to determine the description and relation between risk factors with hypertension. Methods : Observational study with cross sectional design. The study was conducted in the village of Sungai Asam at Koni Public Health Center, Jambi City in 2018. Samples 200 respondents aged $\geq 15$ years were selected by multistage sampling or two stage cluster sampling. Data analysis using by Chi Square test. Results : The proportion of hypertension in Sungai Asam village was 53,5\%. From the 200 respondents there were $60 \%$ had a family history and the most from biological mother $(59,4 \%), 84 \%$ had stress, $80 \%$ consumed salt $>2000 \mathrm{mg} / \mathrm{day}$, $69 \%$ consumed fat foods $>67 \mathrm{gr} /$ day, $94 \%$ consumed vegetables and fruits $<400 \mathrm{gr} / \mathrm{day}(94 \%)$, and $88 \%$ used tobacco and the most are passive smokers $(64,4 \%)$. The risk factors related with hypertension were fat foods consumption $(\mathrm{P}$ value $=0,000 ; \mathrm{POR}=32,300 ; 95 \% \mathrm{CI}=12,002-86,925)$, stress $(\mathrm{P}$ value $=0,000 ; \mathrm{POR}=8,345$; $95 \% \mathrm{CI}=3,060-22,758)$, family history ( $\mathrm{P}$ value $=0,000 ; \mathrm{POR}=7,106$; dan 95\% CI = 3,759-13,436), and salt intake $(\mathrm{P}$ value $=0,000 ; \mathrm{POR}=5,444 ; 95 \% \mathrm{CI}=2,428-12,207)$. Conclusion : Hypertension proven related with family history and other risk factors. Therefore, people need to improve lifestyles that are at risk of developing hypertension especially those with a family history of hypertension.
\end{abstract}

Keywords : Risk Factors, Hypertension, Sungai Asam Village

Korespondensi : Dena

Email : dena35tri@gmail.com 


\section{PENDAHULUAN}

Perubahan pola penyakit dari penyakit menular ke penyakit tidak menular dialami masyarakat baik di negara maju maupun negara dengan keterbatasan sumber daya. Bahkan penyakit tidak menular seperti kardiovaskular telah mengambil alih penyakit menular sebagai penyebab utama kematian ${ }^{1-3}$. Hipertensi merupakan salah satu penyakit tidak menular yang termasuk faktor risiko utama untuk penyakit kardiovaskular seperti jantung dan stroke; dan faktor risiko nomor tiga etiologi kematian di dunia. Dimana sekitar 51\% kematian akibat stroke dan $45 \%$ penyakit jantung koroner disebabkan hipertensi. Adapun hipertensi menyebabkan 9,4 juta kematian di seluruh dunia setiap tahun ${ }^{1-3,5}$.

Indonesia termasuk negara berkembang dengan masalah kesehatan yang serius adalah hipertensi. Dibuktikan dengan prevalensi hipertensi yang cukup signifikan sebesar $26,5 \%{ }^{4,6}$. Jenis hipertensi yang paling banyak dialami masyarakat Indonesia adalah hipertensi primer atau hipertensi esensial ${ }^{3-4,7}$.

Di Provinsi Jambi prevalensi mencapai 24,6\%. Tahun 2007 - 2013, Kota Jambi mengalami peningkatan prevalensi sebesar $4 \%$, sedangkan Kabupaten/Kota lainnya mengalami penurunan $^{9-10}$. Puskesmas Koni merupakan wilayah kerja puskesmas dengan prevalensi hipertensi esensial tertinggi nomor dua setelah Puskesmas Olak Kemang. Bahkan prevalensi hipertensi di wilayah kerja puskesmas Koni mengalami kenaikan yang tertinggi diantara 20 puskesmas di Kota Jambi yang mencapai $7,88 \%$.

Wilayah kerja Puskesmas Koni terdiri dari empat kelurahan, salah satunya adalah kelurahan Sungai Asam yang memiliki masalah hipertensi paling tinggi dibuktikan dengan proporsi jumlah kunjungan kasus hipertensi yang cukup signifikan sebesar $18,8 \%$.

\section{METODE}

Jenis penelitian yang digunakan adalah studi observasional (non eksperimental) dengan rancangan penelitian cross sectional. Penelitian dilakukan di Kelurahan Sungai Asam Wilayah Kerja Puskesmas Koni Kota Jambi. Selanjutnya, penelitian ini dilakukan pada bulan Oktober 2017 sampai dengan Mei 2018. Populasi dalam penelitian ini adalah semua penduduk 15 tahun ke atas yang bertempat tinggal di Kelurahan Sungai Asam yang berjumlah 5397 orang dan sampel sebanyak 200 orang. Sampel yang akan peneliti jadikan responden dipilih menggunakan teknik sampel probabilitas (probability sample), dimana salah satunya adalah multistage sampling atau two stage cluster sampling.

\section{HASIL DAN PEMBAHASAN}

Hasil penelitian ini memaparkan hasil analisis univariat dan bivariat. Analisis univariat dilakukan untuk mengetahui gambaran umum responden meliputi distribusi frekuensi responden berdasarkan karakteristik responden, dan distribusi frekuensi berdasarkan variabel dependen dan variabel independen. Sedangkan analisis bivariat dilakukan untuk mengetahui hubungan antara riwayat keluarga, stres, konsumsi garam, konsumsi makanan berlemak, konsumsi sayur dan buah, penggunaan tembakau dengan hipertensi.

\section{Gambaran Umum Responden}

Tabel 1 menunjukkan bahwa distribusi frekuensi berdasarkan karakteristik responden lebih besar pada jenis kelamin perempuan (57,5\%), kelompok umur 55-64 tahun $(39,5 \%)$, pendidikan terakhir tamat SLTA/ MA atau sederajat (41,5\%), status tidak bekerja $(52,5 \%)$, responden berstatus bekerja dengan jenis pekerjaan utama wiraswasta $(52,6 \%)$, dan tidak berpenghasilan $(53 \%)$. 
Tabel 1. Distribusi Frekuensi Responden Berdasarkan Karakteristik Responden di Kelurahan Sungai Asam Wilayah Kerja Puskesmas Koni

\begin{tabular}{|c|c|c|c|}
\hline No & $\begin{array}{c}\text { Kota Jambi T } \\
\text { Variabel }\end{array}$ & $\begin{array}{l}2018 \\
\text { Jumlah }\end{array}$ & Presentase \\
\hline \multirow[t]{3}{*}{1} & Jenis Kelamin & & \\
\hline & Laki-laki & 85 & 42,5 \\
\hline & Perempuan & 115 & 57,5 \\
\hline \multirow[t]{8}{*}{2} & Umur (tahun) & & \\
\hline & $15-24$ & 8 & 4 \\
\hline & $25-34$ & 20 & 10 \\
\hline & $35-44$ & 20 & 10 \\
\hline & $45-54$ & 20 & 10 \\
\hline & $55-64$ & 79 & 39,5 \\
\hline & $65-74$ & 39 & 7 \\
\hline & $\geq 75$ & 14 & 19,5 \\
\hline \multirow[t]{8}{*}{3} & Pendidikan & & \\
\hline & Tidak/ belum pernah sekolah & 2 & 1 \\
\hline & Tidak tamat SD/MI & 24 & 12 \\
\hline & Tamat SD/MI & 41 & 20,5 \\
\hline & Tamat SLTP/MTS & 27 & 13,5 \\
\hline & Tamat SLTA/MA & 83 & 41,5 \\
\hline & Tamat D1/D2/D3 & 15 & 7,5 \\
\hline & Tamat Perguruan Tinggi & 8 & 4 \\
\hline \multirow[t]{3}{*}{4} & Status Pekerjaan & & \\
\hline & Bekerja & 95 & 47,5 \\
\hline & Tidak Bekerja & 105 & 52,5 \\
\hline \multirow[t]{8}{*}{5} & Jenis Pekerjaan Utama & & \\
\hline & PNS/TNI/POLRI/BUMN/BUMD & 8 & 8,4 \\
\hline & Pegawai Swasta & 8 & 8,4 \\
\hline & Wiraswasta & 50 & 52,6 \\
\hline & Petani & 0 & 0 \\
\hline & Nelayan & 0 & 0 \\
\hline & Buruh & 1 & 1,1 \\
\hline & Lainnya & 28 & 29,5 \\
\hline \multirow[t]{6}{*}{6} & Penghasilan/Pendapatan & & \\
\hline & Tidak berpenghasilan & 106 & 53 \\
\hline & $<1.000 .000$ & 11 & 5,5 \\
\hline & $\geq 1.000 .000-2.500 .000$ & 31 & 15,5 \\
\hline & $>2.500 .000-5.000 .000$ & 39 & 19,5 \\
\hline & $>5.000 .000$ & 13 & 6,5 \\
\hline
\end{tabular}

Tabel 2 menunjukkan bahwa proporsi hipertensi di Kelurahan Sungai Asam sebesar 53,5\%. Selain itu, distribusi frekuensi responden berdasarkan variabel faktor risiko lebih besar pada responden yang memiliki riwayat keluarga hipertensi (60\%) dan paling besar berasal dari ibu kandung $(59,4 \%)$, responden mengalami stres $(84 \%)$, responden sering mengonsumsi garam atau lebih dari $2000 \mathrm{mg}$ per hari (80\%), responden sering mengonsumsi makanan berlemak atau lebih dari 67 gram per hari (69\%), responden kurang mengonsumsi sayur dan buah atau kurang dari 400 gram per hari (94\%), dan menggunakan tembakau (88\%) dan paling besar adalah perokok pasif $(64,4 \%)$. 
Tabel 2 Distribusi Responden Berdasarkan Variabel Dependen (Hipertensi) dan Variabel Independen (Faktor Risiko) di Kelurahan Sungai Asam Wilayah Kerja Puskesmas Koni Kota Jambi Tahun 2018

\begin{tabular}{|c|c|c|c|}
\hline No & Variabel & Jumlah & Presentase \\
\hline \multirow[t]{4}{*}{1} & Hipertensi & & \\
\hline & Iya & 107 & 53,5 \\
\hline & Tidak & 93 & 46,5 \\
\hline & Jumlah & 200 & 100 \\
\hline \multirow[t]{9}{*}{2} & Riwayat Keluarga & & \\
\hline & Iya & 120 & 60 \\
\hline & Tidak & 80 & 40 \\
\hline & Keluarga dengan Hipertensi & & \\
\hline & Ibu & 79 & 59,4 \\
\hline & Ayah & 41 & 30,8 \\
\hline & Nenek & 5 & 3,8 \\
\hline & Kakek & 2 & 1,5 \\
\hline & Saudara Kandung & 6 & 4,5 \\
\hline \multirow[t]{3}{*}{3} & Stres & & \\
\hline & Iya & 168 & 84 \\
\hline & Tidak & 32 & 16 \\
\hline \multirow[t]{3}{*}{4} & Konsumsi Garam & & \\
\hline & Sering (> $2000 \mathrm{mg} /$ hari) & 160 & 80 \\
\hline & Jarang ( $\leq 2000 \mathrm{mg} /$ hari $)$ & 40 & 20 \\
\hline \multirow[t]{3}{*}{5} & Konsumsi Makanan Berlemak & & \\
\hline & Sering (> 67 gram/ hari) & 138 & 69 \\
\hline & Jarang ( $\leq 67$ gram/ hari) & 62 & 31 \\
\hline \multirow[t]{3}{*}{6} & Konsumsi Sayur dan Buah & & \\
\hline & Kurang (<400 gram/ hari) & 105 & 94 \\
\hline & Cukup ( $\geq 400$ gram/ hari) & 95 & 6 \\
\hline \multirow[t]{7}{*}{7} & Penggunaan Tembakau & & \\
\hline & Iya & 176 & 88 \\
\hline & Tidak & 24 & 12 \\
\hline & Kategori Perokok & & \\
\hline & Perokok Aktif & 76 & 28,8 \\
\hline & Perokok Pasif & 170 & 64,4 \\
\hline & Mengunyah Tembakau & 18 & 6,8 \\
\hline
\end{tabular}

\section{Hubungan Faktor Risiko dengan Hipertensi}

Hasil pengukuran tekanan darah yang dilakukan di Kelurahan Sungai Asam menunjukkan bahwa sebanyak 107 orang dari 200 orang memiliki tekanan darah diatas 140/90 mmHg. Jika dibandingkan dengan prevalensi hipertensi di Kota Jambi, proporsi hipertensi di Kelurahan Sungai Asam dua kali lipat lebih tinggi.

Menurut peneliti, tingginya proporsi hipertensi di Kelurahan Sungai Asam dapat disebabkan oleh beberapa faktor seperti tidak diketahui prevalensi hipertensi terkini karena belum ada penelitian setelah penelitian pada tahun 2013 di Provinsi
Jambi terutama di Kota Jambi melalui Riset Kesehatan Dasar (Riskesdas). Selain itu, proporsi hipertensi yang tinggi di Kelurahan Sungai Asam dapat dikaitkan dengan arus globalisasi yang semakin berkembang dari tahun ke tahun dapat memberikan pengaruh terhadap gaya hidup masyarakat yang tidak sehat sehingga mengakibatkan banyak masyarakat mengalami hipertensi atau tekanan darah tinggi.

Adapun faktor yang menyebabkan sebagian besar masyarakat baru menyadari atau mengetahui dirinya memiliki tekanan darah tinggi adalah kurangnya pengetahuan dan kesadaran masyarakat tentang 
pentingnya pengukuran tekanan darah secara teratur minimal satu bulan sekali, dan program Posbindu PTM di Puskesmas Koni yang tidak terlaksana secara efektif.

Peneliti berasumsi bahwa masyarakat akan rutin melakukan pengecekan tekanan darah dan mengendalikan faktor risiko hipertensi apabila dibekali pengetahuan dan kesadaran tentang hipertensi. Tentu saja hal tersebut tidak terlepas dari peran penting Pusat Kesehatan Masyarakat atau disingkat dengan Puskesmas. Permenkes RI nomor 75 tahun 2014, pada Bab 1 pasal 2 dan 4 tentang Puskesmas sebagai salah satu jenis fasilitas pelayanan kesehatan tingkat pertama yang lebih mengutamakan upaya promotif dan preventif.

Setiap kegiatan Puskesmas bertujuan untuk memelihara dan meningkatkan kesehatan serta mencegah dan menanggulangi timbulnya masalah kesehatan. Seperti diketahui bahwa hipertensi dapat dicegah dengan mengendalikan faktor risiko. Sasaran upaya pencegahan tersebut meliputi masyarakat yang tidak memiliki faktor risiko agar tidak timbul faktor risiko hipertensi, masyarakat yang memiliki faktor risiko diupayakan agar kondisi faktor risiko hipertensi menjadi normal kembali dan atau mencegah terjadinya hipertensi, dan masyarakat yang menderita hipertensi diupayakan untuk mencegah komplikasi, kecacatan dan kematian dini serta meningkatkan kualitas hidup.

Salah satu strategi pengendalian hipertensi yang efisien dan efektif adalah pemberdayaan dan peningkatan peran serta masyarakat melalui kegiatan yang disebut dengan Pos Pembinaan Terpadu (Posbindu) PTM.

Hipertensi dapat terjadi karena adanya interaksi berbagai faktor risiko ${ }^{11}$. Dalam penelitian ini, faktor risiko hipertensi meliputi riwayat keluarga, stres, konsumsi garam, konsumsi makanan berlemak, konsumsi sayur dan buah, dan penggunaan temabakau dikatakan memiliki hubungan secara bermakna dengan hipertensi ditunjukkan dengan nilai $\mathrm{P}<0,05$, nilai prevalence odds ratio (POR) $>1$ dan $95 \%$ Confidence Interval tidak mencakup nilai 1.

Tabel 3 Hubungan Faktor Risiko dengan Hipertensi di Kelurahan Sungai Asam Wilayah Kerja Puskesmas Koni Kota Jambi Tahun 2018

\begin{tabular}{|c|c|c|c|c|c|c|c|c|}
\hline \multirow{3}{*}{ No } & \multirow{3}{*}{ Variabel } & \multicolumn{4}{|c|}{ Hipertensi } & \multirow{3}{*}{ Nilai P } & \multirow{3}{*}{ POR } & \multirow{3}{*}{$95 \% \mathrm{CI}$} \\
\hline & & \multicolumn{2}{|c|}{ Iya } & \multicolumn{2}{|c|}{ Tidak } & & & \\
\hline & & $\mathbf{n}$ & $\%$ & $\mathbf{n}$ & $\%$ & & & \\
\hline \multirow[t]{3}{*}{1} & Riwayat Kel & & & & & & & \\
\hline & Iya & 86 & 80,4 & 34 & 36,6 & 0,000 & 7,106 & $3,759-13,436$ \\
\hline & Tidak & 21 & 19,6 & 59 & 63,4 & & & \\
\hline \multirow[t]{3}{*}{2} & Stres & & & & & & & \\
\hline & Iya & 102 & 95,3 & 66 & 71 & 0,000 & 8,345 & $3,060-22,758$ \\
\hline & Tidak & 5 & 4,7 & 27 & 29 & & & \\
\hline \multirow[t]{3}{*}{3} & Konsumsi G & & & & & & & \\
\hline & Sering & 98 & 91,6 & 62 & 66,7 & 0,000 & 5,444 & $2,428-12,207$ \\
\hline & Jarang & 9 & 8,4 & 31 & 33,3 & & & \\
\hline \multirow[t]{3}{*}{4} & Konsumsi M & an $B$ & emak & & & & & \\
\hline & Sering & 102 & 95,3 & 36 & 38,7 & 0,000 & 32,300 & $12,002-86,925$ \\
\hline & Jarang & 5 & 4,7 & 57 & 61,3 & & & \\
\hline \multirow[t]{3}{*}{5} & Konsumsi Sa & $\operatorname{lan} B$ & & & & & & \\
\hline & Kurang & 58 & 54,2 & 47 & 50,5 & 0,707 & 1,158 & $0,664-2,021$ \\
\hline & Cukup & 49 & 50,8 & 46 & 49,5 & & & \\
\hline \multirow[t]{3}{*}{6} & Penggunaan & baka & & & & & & \\
\hline & Iya & 92 & 86 & 84 & 90,3 & 0,469 & 0,657 & $0,273-1,581$ \\
\hline & Tidak & 15 & 14 & 9 & 9,7 & & & \\
\hline
\end{tabular}


Berdasarkan hasil analisis terbukti bahwa riwayat keluarga, stres, konsumsi garam, dan konsumsi makanan berlemak berhubungan dengan hipertensi. Adapun faktor risiko yang memiliki risiko paling besar terhadap hipertensi di Kelurahan Sungai Asam adalah konsumsi makanan berlemak (nilai $\mathrm{P}=0,000$; $\mathrm{POR}=32,300$; 95\% CI $=12,002-86,925$ ), stres (nilai $\mathrm{P}=$ 0,$000 ;$ POR $=8,345 ; 95 \% \mathrm{CI}=3,060-$ 22,758), riwayat keluarga (nilai $\mathrm{P}=0,000$; $\mathrm{POR}=7,106$; dan 95\% CI = 3,759-13,436), konsumsi garam (nilai $\mathrm{P}=0,000$; $\mathrm{POR}=$ 5,444; 95\% CI = 2,428-12,207). Sedangkan faktor risiko yang tidak berhubungan dengan hipertensi adalah konsumsi sayur dan buah (nilai $\mathrm{P}=0,707$; $\mathrm{POR}=1,158$; 95\% $\mathrm{CI}=0,664-2,021)$, dan penggunaan tembakau (nilai $\mathrm{P}=0,469$; $\mathrm{POR}=0,657$; $95 \% \mathrm{CI}=0,273-1,581)$.

\section{a. Konsumsi Makanan Berlemak}

Konsumsi makanan berlemak dalam penelitian ini difokuskan terhadap semua makanan yang memiliki kandungan baik rendah lemak, lemak sedang, maupun tinggi lemak. Konsumsi makanan berlemak di Kelurahan Sungai Asam menjadi faktor risiko yang memiliki risiko paling besar menyebabkan hipertensi diantara faktor risiko lain yang diteliti. Dibuktikan dengan hasil analisis bivariat yang menunjukkan bahwa seseorang yang mengonsumsi makanan berlemak >67 gram per hari memiliki risiko terkena hipertensi sebanyak 32,300 kali lebih besar bila dibandingkan dengan seseorang yang mengonsumsi makanan berlemak $\leq 67$ gram per hari.

Hasil penelitian ini sejalan dengan penelitian yang dilakukan di Desa Tandengan Satu Kecamatan Eris Kabupaten Minahasa menunjukkan bahwa terdapat hubungan antara asupan lemak dengan kejadian hipertensi dengan nilai $\mathrm{P}=$ $0,000^{12}$. Selain itu, penelitian lain yang menunjukkan bahwa seseorang yang mengonsumsi makanan berlemak berlebih berisiko terkena hipertensi 3,6 kali lebih tinggi dibandingkan dengan seseorang yang cukup mengonsumsi makanan berlemak ${ }^{13}$.

Berdasarkan informasi karakteristik responden yaitu tingkat penghasilan yang menunjukkan sebesar 53\% responden tidak berpenghasilan, sehingga dapat diasumsikan bahwa rendahnya ekonomi (penghasilan) menyebabkan akses ke pelayanan kesehatan kurang dan dapat mengakibatkan rendahnya pengetahuan terutama tentang kuantitas dan kualitas konsumsi makanan berlemak yang sesuai dengan kebutuhan seharusnya. Dengan demikian, tingkat penghasilan secara tidak langsung mempengaruhi hubungan antara konsumsi makanan berlemak dengan hipertensi di Kelurahan Sungai Asam.

Di Puskesmas Koni Kota Jambi tahun 2017, upaya pencegahan dan pengendalian hipertensi terkait dengan konsumsi makanan berlemak telah dilakukan melalui kegiatan Posbindu PTM. Adapun upaya yang dilakukan adalah kegiatan konseling dan penyuluhan kepada masyarakat. Kegiatan tersebut bertujuan agar masyarakat tahu langkah yang tepat mengendalikan faktor risiko hipertensi terutama konsumsi makanan berlemak yang menjadi faktor risiko utama hipertensi di Kelurahan Sungai Asam.

Berdasarkan wawancara dengan tenaga kesehatan yang ada di Puskesmas Koni, kegiatan Posbindu PTM dilaksanakan rutin setiap bulan, namun masih kurang optimal disebabkan beberapa faktor antara lain kurangnya sumber daya manusia yang mau dan mampu menjadi pelaku kegiatan Posbindu, dan terdapat kader yang kurang memahami tugas dan fungsi kader Posbindu PTM karena tidak ada pelatihan kader. Selain Posbindu PTM, konseling PTM menjadi salah satu program Puskesmas Koni. Namun, program tersebut belum optimal dilaksanakan karena masyarakat menganggap dirinya dalam keadaan sehat sehingga merasa tidak memerlukan adanya konseling. 


\section{b. Stres}

Etiologi utama hipertensi yaitu gaya hidup yang modern, sebab dalam gaya hidup modern situasi penuh tekanan dan stres. Dalam kondisi tertekan, adrenalin dan kortisol dilepaskan ke aliran darah sehingga menyebabkan peningkatan tekanan darah ${ }^{14}$.

Hasil penelitian ini ditemukan sebanyak 84\% mengalami stres dalam 30 hari selama penelitian berlangsung. Selain itu, hasil penelitian juga menunjukkan bahwa seseorang dengan kondisi stres memiliki risiko terkena hipertensi 8,345 kali lebih besar bila dibandingkan seseorang dengan kondisi tidak mengalami stres. Diperoleh informasi yang menunjukkan sebanyak $60 \%$ stres diekpresikan dalam sikap tegang, cemas, dan atau khawatir.

Stres dapat meningkatkan tekanan darah dalam jangka waktu pendek dengan cara mengaktifkan bagian otak dan sistem saraf yang biasanya mengendalikan tekanan darah secara otomatis ${ }^{15}$. Hormon adrenalin akan meningkat sewaktu seseorang mengalami stres, dan hal tersebut dapat mengakibatkan jantung memompa darah lebih cepat sehingga tekanan darah pun meningkat ${ }^{16}$.

Penelitian sebelumnya menunjukkan bahwa terdapat hubungan antara stres dengan kejadian hipertensi dengan nilai $\mathrm{p}=$ $0,002^{17}$. Begitu pula dengan penelitian yang dilakukan di Desa Tarabitan Kecamatan Likupang Barat Kabupaten Minahasa Utara didapatkan nilai $\mathrm{p}=0,000$ artinya terdapat hubungan antara stres dengan kejadian hipertensi ${ }^{18}$. Berdasarkan penelitian di Wilayah Kerja Puskesmas Andalas Padang tahun 2015 diperoleh nilai korelasi spearman sebesar 0,486 memiliki kekuatan hubungan sedang dengan arah korelasi positif artinya semakin tinggi tingkat stres maka semakin tinggi derajat hipertensi ${ }^{19}$.

Dari hasil penelitian, diperoleh informasi status pekerjaan dan jenis pekerjaan utama responden yakni sebesar 52,5\% responden tidak bekerja, dan dari $47,5 \%$ responden yang bekerja sebanyak $52,6 \%$ memiliki pekerjaan utama wiraswasta. Status tidak bekerja secara tidak langsung berhubungan dengan tekanan darah melalui kurangnya aktifitas fisik yang dilakukan. Sedangkan, seseorang yang bekerja lebih mudah mengalami tekanan atau stres. Sehingga hal tersebut dapat memperkuat hubungan antara stres dengan hipertensi di Kelurahan Sungai Asam.

Di Puskesmas Koni Kota Jambi tahun 2017, upaya pencegahan dan pengendalian hipertensi terkait dengan faktor stres telah dilakukan melalui kegiatan Posbindu PTM. Adapun upaya yang dilakukan adalah kegiatan konseling dan penyuluhan kepada masyarakat. Kegiatan tersebut bertujuan agar masyarakat tahu langkah yang tepat mengendalikan faktor risiko hipertensi terutama faktor stres. Namun, kegiatan konseling dan penyuluhan tentang faktor risiko hipertensi termasuk stres dan langkah yang tepat dalam mengelola stres tidak berjalan dengan baik. Sehingga masih banyak masyarakat yang mengalami stres akibat pekerjaan, ekonomi, dan rumah tangga sehingga berisiko mengalami hipertensi.

\section{c. Riwayat Keluarga}

Riwayat keluarga yang menderita hipertensi (faktor keturunan) juga mempertinggi risiko terkena hipertensi terutama pada hipertensi esensial/ primer. Riwayat keluarga yang menderita hipertensi terbukti merupakan faktor risiko terjadinya hipertensi, dibuktikan dengan hasil penelitian yang menunjukkan bahwa seseorang dengan riwayat keluarga menderita hipertensi memiliki risiko terkena hipertensi 7,106 kali lebih besar bila dibandingkan dengan seseorang yang tidak ada riwayat keluarga hipertensi. Dari hasil penelitian ini diketahui bahwa riwayat keluarga hipertensi paling banyak diperoleh dari ibu kandung $(59,4 \%)$.

Riwayat keluarga dapat dianggap sebagai peluang untuk melibatkan anggota keluarga langsung dalam pendidikan kesehatan, serta untuk intervensi dini dan meningkatkan kontrol hipertensi ${ }^{20}$. Sehingga dengan adanya faktor genetik pada keluarga tertentu seperti ibu/ ayah, nenek/ kakek, dan saudara kandung akan 
menyebabkan keluarga itu mempunyai risiko menderita hipertensi ${ }^{21}$. Hal tersebut berhubungan dengan peningkatan kadar sodium intraselular dan rendahnya rasio antara potassium terhadap sodium. Individu orang tua menderita hipertensi mempunyai risiko dua kali lebih besar untuk menderita hipertensi dibandingkan orang yang tidak memiliki keluarga dengan riwayat hipertensi ${ }^{22}$.

Penelitian ini sejalan dengan penelitian di Wilayah Kerja Puskesmas Segeri Kabupaten Pangkep yang menyimpulkan bahwa ada hubungan antara riwayat keluarga dengan dengan kejadian hipertensi ${ }^{23}$. Sedangkan, hasil penelitian di Puskesmas Srondol Semarang menunjukkan hal yang berbeda bahwa tidak ada hubungan yang bermakna secara statistik antara riwayat keluarga dengan kejadian hipertensi ${ }^{24}$

Salah satu bentuk kegiatan Posbindu PTM terkait dengan penanganan riwayat keluarga dengan hipertensi adalah kegiatan penggalian informasi faktor risiko dengan wawancara sederhana yang dilakukan saat pertama kali kunjungan dan berkala sebulan sekali. Namun, berdasarkan informasi dari penanggung jawab program Posbindu PTM di Puskesmas Koni, kegiatan tersebut tidak dilaksanakan di wilayah kerja Puskesmas Koni.

\section{d. Konsumsi Garam}

Berdasarkan penelitian didapatkan informasi bahwa sebanyak $80 \%$ responden mengonsumsi garam yang tidak sesuai dengan anjuran Kementerian Kesehatan melalui Pedoman Gizi Seimbang yaitu konsumsi garam >2000 mg per hari atau setara dengan 1 sendok teh per hari. Dalam penelitian ini, konsumsi garam terbukti merupakan faktor risiko terjadinya hipertensi di Kelurahan Sungai Asam dengan hasil analisis bivariat yang menunjukkan bahwa seseorang yang mengonsumsi garam >2000 mg per hari memiliki risiko terkena hipertensi 5,444 kali lebih besar bila dibandingkan dengan seseorang yang mengonsumsi garam $\leq 2000$ mg per hari.

Konsumsi garam yang berlebihan dapat meningkatkan tekanan darah karena garam bersifat menahan air sehingga volume darah meningkat dan menyebabkan penyempitan diameter pembuluh darah arteri. Keadaan ini memaksa jantung memompa lebih kuat, sehingga tekanan darah meningkat ${ }^{25,4}$. Sedangkan sebagian besar masyarakat tidak menyadari sepenuhnya bahwa kebiasaan mengonsumsi garam/ makanan asin merupakan faktor risiko terjadinya hipertensi ${ }^{4}$. Kebanyakan dari mereka tidak bisa menghindari kebiasaan mengonsumsi garam karena mereka sudah terbiasa masak dengan menggunakan garam ${ }^{26}$.

Hasil penelitian ini sejalan dengan penelitian yang dilakukan di Puskesmas Tlogosari Kulon Kota Semarang yang menunjukkan bahwa ada hubungan yang bermakna antara kebiasaan konsumsi garam dengan kejadian hipertensi. Penelitian tersebut menunjukkan kebiasaan sering mengonsumsi garam 4,9 kali lebih berisiko terkena hipertensi dibandingkan jarang mengonsumsi garam ${ }^{13}$.

Di Puskesmas Koni Kota Jambi tahun 2017, upaya pencegahan dan pengendalian hipertensi terkait dengan konsumsi garam telah dilakukan melalui kegiatan Posbindu PTM. Adapun upaya yang dilakukan adalah kegiatan konseling dan penyuluhan kepada masyarakat. Kegiatan tersebut bertujuan agar masyarakat tahu langkah yang tepat mengendalikan faktor risiko hipertensi terutama konsumsi garam atau makanan yang mengandung garam.

Berdasarkan wawancara dengan tenaga kesehatan yang ada di Puskesmas Koni, kegiatan Posbindu PTM dilaksanakan rutin setiap bulan, namun masih kurang optimal disebabkan beberapa faktor antara lain kurangnya sumber daya manusia yang mau dan mampu menjadi pelaku kegiatan Posbindu, dan terdapat kader yang kurang memahami tugas dan fungsi kader Posbindu PTM karena tidak ada pelatihan kader. Selain Posbindu PTM, konseling PTM menjadi salah satu program Puskesmas 
Koni. Namun, program tersebut belum optimal dilaksanakan karena masyarakat menganggap dirinya dalam keadaan sehat sehingga merasa tidak memerlukan adanya konseling.

\section{e. Konsumsi Sayur dan Buah}

Penelitian ini menunjukkan bahwa hanya $6 \%$ responden yang mengonsumsi sayur dan buah dalam jumlah yang cukup atau setara dengan 400 gram atau lebih per hari. Dan Berdasarkan analisis bivariat, responden yang menderita hipertensi dan tidak hipertensi sama-sama mengonsumsi sayur dan buah dalam jumlah yang kurang. Sehingga hal tersebut menyebabkan konsumsi sayur dan buah tidak berhubungan dengan hipertensi. Namun, hasil analisis menunjukkan responden yang mengonsumsi sayur dan buah kurang dari 400 gram per hari memiliki kecenderungan sebagai faktor risiko hipertensi sebesar 1,158 kali dibandingkan dengan responden yang mengonsumsi sayur dan buah 400 gram atau lebih per hari.

Meskipun secara statistik ditemukan bahwa tidak ada hubungan antara konsumsi sayur dan huah dengan kejadian hipertensi, tetapi secara teoritis hal ini telah sesuai bahwa rutin mengonsumsi sayur dan buah dalam jumlah yang cukup dapat menurunkan risiko hipertensi ${ }^{4}$. Penelitian ini sejalan dengan hasil penelitian yang menunjukkan bahwa tidak ada hubungan antara konsumsi sayur dan buah dengan kejadian hipertensi di Wilayah Kerja Puskesmas Segeri Kabupaten Pangkep ${ }^{23}$. Penelitian sebelumnya menunjukkan bahwa konsumsi sayur dan buah yang cukup 5,3 kali berisiko terhadap kejadian hipertensi dibandingkan konsumsi sayur dan buah yang lebih ${ }^{28}$.

\section{f. Penggunaan Tembakau}

Hasil analisis tabel silang menunjukkan sebesar $64,4 \%$ penggunaan tembakau di Kelurahan Sungai Asam berasal dari perokok pasif. Dan berdasarkan analisis menggunakan uji chi square penggunaan tembakau terbukti tidak berhubungan dengan hipertensi di Kelurahan Sungai Asam. Menurut peneliti, hal tersebut disebabkan karena antara jumlah penggunaan tembakau pada responden hipertensi dan penggunaan tembakau pada responden yang tidak mengalami hipertensi relatif sama, yaitu sebesar $86 \%$ pada responden hipertensi dan 90,3\% pada responden tidak hipertensi.

Penelitian ini sejalan dengan penelitian sebelumnya yang menunjukkan bahwa tidak terdapat hubungan yang bermakna secara statistik antara perilaku merokok dengan kejadian hipertensi di Puskesmas Srondol Semarang dengan nilai $p=0,057^{24}$. Selain itu, penelitian yang dilakukan di Puskesmas Tlogosari Kulon Kota Semarang juga menunjukkan hak yang sama bahwa berdasarkan hasil uji statistik chi-square diperoleh nilai $\mathrm{p}=0,655 ; \mathrm{OR}=1,1 ; 95 \% \mathrm{CI}$ $=0,4-3,3$. Nilai $\mathrm{p}>0,05$ yang berarti tidak ada hubungan yang bermakna antara kebiasaan merokok dengan kejadian hipertensi ${ }^{13}$.

Namun, hal berbeda menunjukkan bahwa terdapat hubungan antara merokok dengan kejadian hipertensi ${ }^{17}$. Nikotin yang terkandung didalam batang rokok yang dihisap seseorang merangsang terjadinya peningkatan tekanan darah. Selain itu, orang yang menggunakan tembakau akan mencederai dinding pembuluh darah dan mempercepat pembentukan aterosklerosis (pengerasan pembuluh darah), membuat jantung bekerja lebih keras karena menyempitkan pembuluh darah untuk sementara dan meningkatkan frekuensi denyut jantung serta tekanan darah ${ }^{15}$. Hal tersebut kemungkinan disebabkan variabel penggunaan tembakau baik pada penderita maupun bukan penderita hipertensi hampir sama.

\section{KESIMPULAN}

Hasil analisis univariat menunjukkan bahwa distribusi frekuensi responden dalam penelitian ini paling banyak yaitu perempuan, kelompok umur 55-64 tahun, pendidikan terakhir tamat SLTA/ MA atau sederajat, status 
tidak bekerja, responden berstatus bekerja dengan jenis pekerjaan utama wiraswasta, dan tidak berpenghasilan, mengalami hipertensi, ada riwayat keluarga hipertensi dan paling besar berasal dari ibu kandung, mengalami stres, mengonsumsi garam lebih dari $2000 \mathrm{mg}$ per hari, mengonsumsi makanan berlemak lebih dari 67 gram per hari, mengonsumsi sayur dan buah kurang dari 400 gram per hari, dan menggunakan tembakau dan paling besar adalah perokok pasif.

Hasil analisis bivariat menunjukkan bahwa ada hubungan antara riwayat keluarga, stres, konsumsi garam, dan konsumsi makanan berlemak dengan hipertensi di Kelurahan Sungai Asam Kota Jambi. Diantara faktor risiko tersebut, konsumsi makanan berlemak menjadi faktor risiko paling besar untuk terkena hipertensi. Sedangkan, konsumsi sayur buah, dan penggunaan tembakau tidak berhubungan dengan hipertensi di Kelurahan Sungai Asam Kota Jambi.

\section{SARAN}

\section{Dinas Kesehatan Kota Jambi dan Puskesmas Koni}

Disarankan kepada Dinas Kesehatan Kota Jambi untuk mengoptimalkan dan mengaktifkan kembali kegiatan posbindu PTM di puskesmas - puskesmas yang berada di wilayah kerja Pemerintahan Kota Jambi terutama Puskesmas Koni. Kegiatan yang bersedia dalam rangka mencegah dan mengendalikan faktor risiko hipertensi melalui upaya promotif dan preventif seperti kegiatan sosialisasi dan edukasi guna meningkatkan pemahaman, kesadaran, dan kemauan masyarakat dalam memeriksakan tekanan darah, memperbaiki gaya hidup yang berisiko terhadap hipertensi serta minum obat anti-hipertensi secara rutin bagi kelompok masyarakat yang memiliki faktor risiko untuk terkena hipertensi terutama di Kelurahan Sungai Asam.

Selain itu, melakukan screening kasus hipertensi terutama pada masyarakat umur diatas 40 tahun karena merupakan kelompok risiko tinggi menderita hipertensi.

\section{Masyarakat Kelurahan Sungai Asam}

Sebaiknya melakukan pengukuran tekanan darah secara berkala yang dapat dilakukan di puskesmas Koni atau melalui kegiatan posbindu PTM sehingga dapat melaksanakan upaya-upaya pencegahan dan pengendalian secara dini. Selain itu, diharapkan masyarakat memperbaiki gaya hidup yang berisiko menimbulkan penyakit hipertensi terutama masyarakat yang memiliki riwayat hipertensi pada keluarga.

\section{Fakultas Kesehatan Masyarakat}

Diharapkan dapat dijadikan sebagai masukan bagi Fakultas Kesehatan Masyarakat Program Studi Ilmu Kesehatan Masyarakat, khususnya peminatan Epidemiologi dan Promosi Kesehatan yang dapat bekerja sama dengan mahasiswa untuk meningkatkan upaya promotif dan preventif untuk mengendalikan faktor risiko hipertensi.

\section{Peneliti Lain}

Peneliti selanjutnya disarankan untuk dapat meneliti hipertensi dengan faktor risiko lainnya terutama golongan faktor risiko yang dapat diubah sehingga masyarakat dapat melakukan pencegahan dan pengendalian yang lebih spesifik dan optimal. Peneliti selanjutnya dapat melakukan penelitian dengan menggunakan metode penelitian yang lebih baik seperti Kasus Kontrol, Kohort, dan Eksperimen. Selain itu, peneliti selanjutnya disarankan dapat memperluas populasi penelitian yang kemudian berpengaruh terhadap jumlah sampel yang diteliti, sehingga hasil penelitian tersebut dapat memberikan manfaat untuk masyarakat yang lebih banyak.

\section{DAFTAR PUSTAKA}

1. Bustan., 2000. Epidemiologi Penyakit Tidak Menular. Jakarta: Rineka Cipta.

2. Kemenkes RI, 2012. Masalah Hipertensi di Indonesia. [online] www.depkes.go.id [diakses 08 November 2017] 
3. WHO., 2013. A Global Brief on Hypertension. Switzerland : World Health Organization.

4. Kemenkes RI, 2014. Hipertensi dalam Pusat Data dan Informasi Kesehatan RI. Jakarta Selatan: Infodatin.

5. Bustan., 2007. Manajemen Pengendalian Penyakit Tidak Menular. Jakarta: Rineka Cipta

6. Kemenkes RI, 2013. Riset Kesehatan Dasar (RISKESDAS 2013). Jakarta: Badan Penelitian dan Pengembangan Kesehatan.

7. Masriadi., 2016. Epidemiologi Penyakit Tidak Menular: Hipertensi. Jakarta: CV. Trans Info Media.

8. Kemenkes RI, 2013. Buku Pintar Kader. Penyelenggaraan Posbindu PTM. Jakarta: Direktorat Jenderal Pengendalian Penyakit dan Penyehatan Lingkungan, Direktorat Pengendalian Penyakit Tidak Menular.

9. Departemen Kesehatan Republik Indonesia, 2008. Riset Kesehatan Dasar (RISKESDAS) 2007 : Laporan Nasional 2007. Jakarta: Badan Penelitian dan Pengembangan Kesehatan.

10. Kemenkes RI, 2013. Riset Kesehatan Dasar Dalam Angka Provinsi Jambi. Jakarta: Badan Penelitian dan Pengembangan Kesehatan.

11. WHO., 2014. Know your risk factors for high blood pressure. [online] http://www.heart.org/HEARTORG/Conditi ons/HighBloodPressure/UnderstandSympto msRisks/Know-Your-Risk-Factors-forHigh-Blood-

Pressure_UCM_002052_Article.jsp\#.Wmx vHTeYPIU [diakses 05 November 2017].

12. Manawan dkk, 2016. Hubungan antara Konsumsi Makanan dengan Kejadian Hipertensi di Desa Tandengan Satu Kecamatan Eris Kabupaten Minahasa. Fakultas Kesehatan Masyarakat Universitas Sam Ratulangi. Vol 5 (1) : 340-347.

13. Syahrini, Susanto, Udiyono., 2012. FaktorFaktor Risiko Hipertensi Primer di Puskesmas Tlogosari Kota Semarang.
Jurnal Kesehatan Masyarakat Universitas Diponegoro. Vol 1 (2) : 315-325.

14. Sugiharto., 2007. Faktor-Faktor Risiko Hipertensi Grade II Pada Masyarakat. Studi Kasus di Kabupaten Karanganyar. Semarang: Epidemiologi. Universitas Diponegoro.

15. Darlimartha dkk, 2008. Care Your Self, Hipertensi. Penebar Plus ${ }^{+}$

16. Subramaniam, 2015. Hubungan antara Stres dan Tekanan Darah Tinggi pada Mahasiswa. Fakultas Kedokteran Universitas Udayana. Vol 2 (1) : 4-7.

17. Jannah dkk, 2017. Analisis Faktor Penyebab Kejadian Hipertensi di Wilayah Kerja Puskesmas Mangasa Kecamatan Tamalate Makassar. 3 (1).

18. Manggopa dkk, 2017. Hubungan antara Kebiasaan Merokok dan Stres dengan Kejadian Penyakit Hipertensi di Desa Tarabitan Kecamatan Likupang Barat Kabupaten Minahasa Utara. Vol 6 (3).

19. Saleh dkk, 2014. Hubungan Tingkat Stres dengan Derajat Hipertensi pada Pasien Hipertensi di Wilayah Kerja Puskesmas Andalas Padang Tahun 2014. Program Studi S1 Ilmu Keperawatan Fakultas Keperawatan Universitas Andalas. Vol 10 (1) : 166-175.

20. Van der Sande MA, Walraven GE, Milligan PJ, Banya WA, Ceesay SM, Nyan OA, McAdam KP, 2001. Family history: an opportunity for early interventions and improved control of hypertension, obesity and diabetes. Bull World Health Organ. 79(4):321-8.

21. Yeni dkk, 2010. Faktor-Faktor yang Berhubungan dengan Kejadian Hipertensi Pada Wanita Usia Subur di Puskesmas Umbulharjo Yogyakarta.

22. Pramana., 2016. Faktor yang Berhubungan dengan Tingkat Hipertensi di Wilayah Kerja Puskesmas Demak II. Fakultas Kesehatan Masyarakat. Universitas Muhammadiyah Semarang.

23. Thaha dkk, 2016. Kejadian Hipertensi di Wilayah Kerja Puskesmas Segeri Kabupaten Pangkep. Bagian Epidemiologi 
Fakultas Kesehatan Masyarakat Universitas Hasanuddin.

24. Kurniasih dan Setiawan, 2011. Analisis Faktor Risiko Kejadian Hipertensi di Puskesmas Srondol Semarang Periode Bulan September-Oktober 2011. Fakultas Kedokteran Universitas Muhammadiyah Semarang. Vol 1 (2).

25. Kemenkes RI., 2011. Pedoman Pengendalian Faktor Risiko Penyakit Jantung dan Pembuluh Darah. Jakarta: Direktoral Pengendalian Penyakit Tidak Menular.

26. Herwati dan Sartika., 2013. Terkontrolnya Tekanan Darah Penderita Hipertensi Berdasarkan Pola Diet dan Kebiasaan Olahraga Di Padang Tahun 2011. Jurusan Keperawatan Padang. Poltekkes Kemkes Padang. 8 (1): 8-13.

27. Tambayong, 2000. Patofisiologi Untuk Keperawatan. Penerbit Buku Kedokteran EGC. [online] https://books.google.co.id/books?id=KdJfk 2qazVIC\&pg=PA96\&dq=gejala+hipertensi +esensial\&hl=id\&sa=X\&ved=0ahUKEwjq oLrNo7nbAhUXcCsKHc49CesQ6AEILDA $\mathrm{B} \# \mathrm{v}=$ onepage $\& \mathrm{q} \& \mathrm{f}=$ false [diakses 04 Juni 2018].

28. Anwar, 2014. Konsumsi Buah dan Sayur serta Konsumsi Susu sebagai Faktor Risiko Terjadinya Hipertensi di Puskesmas S. Parman Kota Banjarmasin. Vol 5 (1). 